\title{
High Performance Polymer Blend Systems for HVDC Applications
}

\author{
Ian L. Hosier and Alun S. Vaughan \\ ECS, University of Southampton \\ Southampton, SO17 1BJ, UK \\ Amy Pye and Gary C. Stevens \\ Gnosys Global Ltd, The Surrey Research Park, \\ Guildford, GU2 7YD, UK
}

\begin{abstract}
Two polyethylene and two polypropylene blends crystallized under non-isothermal conditions were compared to a crosslinked polyethylene (XLPE) reference material. Selected blends contained a gelation agent, which forms a network structure within the material. Compared to XLPE, the blends offered higher melting points, reduced electrical conductivity, increased electrical breakdown strength, improved space charge performance and enhanced thermo-mechanical stability. Additional improvements in space charge behavior were also noted in systems containing the DBS gelation agent. The ability to provide recyclable insulation materials capable of operating at much higher temperatures than XLPE, combined with enhanced dielectric properties, may prove advantageous to cable manufacturers, particularly in renewable energy applications.
\end{abstract}

Index Terms - polymer blends, morphology, electrical breakdown strength, space charge, dibenzylidene sorbitol.

\section{INTRODUCTION}

WITH increasing environmental awareness comes the need to develop new recyclable materials for cable applications [1]. For intermittent renewable energy sources, high voltage DC (HVDC) is favored over high voltage AC (HVAC) for long distance links such as interconnects within the proposed European Supergrid [2]. Crosslinked polyethylene (XLPE) is currently favored in HVAC applications due to its low cost, high dielectric strength, low dielectric loss, ease of extrusion and excellent thermo-mechanical stability up to $80^{\circ} \mathrm{C}$ [3]. However, being a thermosetting material, XLPE is not readily recycled and presents new challenges when used in HVDC applications. For instance, by-products from the crosslinking process can lead to heterocharge accumulation within the insulation, leading to premature insulation failure [4], and effective degassing to remove such products is challenging [5]. Material purity is much more important in HVDC than in HVAC applications, bringing a need to develop new ultrapure insulation systems tailored for the new challenges imposed by HVDC. Such systems would ideally; (a) include no cross-linking by-products, (b) be recyclable at end of life, (c) balance mechanical flexibility with excellent dielectric properties and (d) provide sufficient mechanical integrity at cable operating temperatures.
Low-density polyethylene (LDPE) has favorable dielectric and mechanical properties but has poor thermo-mechanical stability at high temperatures $[3,6]$. Whilst high-density polyethylene (HDPE) provides good mechanical stability up to $\sim 120{ }^{\circ} \mathrm{C}$, its mechanical stiffness is undesirable in a cable system. Polymer blends, where a proportion of HDPE is incorporated into a LDPE matrix, still permit operation up to $120^{\circ} \mathrm{C}$ but, additionally, provide improved mechanical flexibility compared to HDPE [6]. Through appropriate isothermal crystallization, they provide superior AC breakdown strength and enhanced thermo-mechanical stability compared to LDPE and XLPE [7,8]. Such enhanced properties translate into improved cable systems when crystallized under more technologically relevant non-isothermal conditions [9].

Polypropylene provides a way of increasing cable operating temperatures even further, by virtue of its increased melting point. Having additional headroom to operate at higher temperatures is highly desirable in renewable sourced power systems, where load patterns are highly variable, and increases operational ratings for the same geometry cable [10]. Whilst isotactic polypropylene has less than desirable mechanical properties - being too brittle for cable applications, syndiotactic polypropylene $[11,12]$ and certain co-polymers with a high ethylene content [1, 12-14] have improved mechanical flexibility. In previous investigations [14], a 1:1 blend of isotactic polypropylene with a co-polymer was shown to have mechanical properties suitable for cables. The system also offered superior thermo-mechanical stability and 
enhanced AC breakdown strength compared to XLPE.

These previous investigations have all focused on HVAC applications, so in this study, analogous polyethylene and polypropylene blends have been studied with an emphasis towards potential HVDC applications. Their properties were compared to an XLPE reference material and a commercial gelation agent was incorporated into the blends as a means of further modifying the morphology and properties of the system [15]. Previous studies have indicated that the incorporation of this additive improves space charge dissipation [16] - a desirable attribute in an HVDC system. Their melting and crystallization behavior was followed by differential scanning calorimetry, their morphology was studied by scanning electron microscopy and additional electrical conductivity, electrical breakdown and space charge measurements were all performed under DC conditions. Finally, their thermo-mechanical stability was considered.

\section{EXPERIMENTAL}

\subsection{MATERIALS AND BLENDING}

Superclean low density polyethylene (LDPE: Exxon Mobil LD100BW), high density polyethylene (HDPE: BP Rigidex HD5813EA), isotactic polypropylene (iPP: Carmel Olefins E65F) and a propylene co-polymer (PCP: Carmel Olefins CL50E) that was specifically chosen for its low mechanical modulus $(450 \mathrm{MPa})$ and relatively high melting point $\left(150{ }^{\circ} \mathrm{C}\right)$ [6] were all used as supplied. From these materials, two polyethylene (PE) and two polypropylene (PP) blends were prepared in $50 \mathrm{~g}$ quantities by melt mixing at 150 and $180{ }^{\circ} \mathrm{C}$ respectively (HAAKE Polylab QC mixer operated at 40 RPM for $20 \mathrm{~min}$ ) as in Table 1. Milliken Millad NX8000 was used as the dibenzylidene sorbitol (DBS) based gelation agent and was added at a fixed $0.5 \mathrm{wt}$. \% concentration [15] to selected blends during the melt mixing phase. Finally, to create superclean crosslinked polyethylene (XLPE), 2 wt. \% [17] of dicumyl peroxide (DCP: Sigma-Adrich) was added to the LDPE through identical melt mixing at $130{ }^{\circ} \mathrm{C}$, the lower temperature being selected to prevent premature crosslinking.

\subsection{SAMPLE PREPARATION}

Samples for testing were prepared using $2 \mathrm{~mm}$ thickness steel sheets lined with Melanex to prevent sticking and appropriate spacers, depending on the required thickness. To prevent premature crosslinking of the XLPE, this was first molded at $130{ }^{\circ} \mathrm{C}$ and, once the sheet had been formed, the temperature was increased to $180{ }^{\circ} \mathrm{C}$ and a pressure of 50 bar was maintained for 10 min to induce crosslinking [5]. In contrast, the PE and PP blends were pressed at 150 and $180{ }^{\circ} \mathrm{C}$ respectively. All samples were then cooled by removing the complete mold assembly from the press and leaving in ambient air for $40 \mathrm{~min}$.

Table 1. Material systems used in these investigations.

\begin{tabular}{l|c}
\hline Designation & Components \\
\hline XLPE & LDPE + 2 wt. \% DCP \\
PE20s & $20 \%$ wt. \% HDPE in LDPE \\
PE20d & As PE20s with 0.5 wt. \% DBS \\
PP50s & 50 wt. \% iPP in PCP \\
PP50d & As PP50s with 0.5 wt. \% DBS \\
\hline
\end{tabular}

By measuring the temperature at regular intervals, plotting and fitting an exponential curve, the cooling rate over the applicable crystallization range $\left(100-120^{\circ} \mathrm{C}\right)$ was found to be $5 \mathrm{~K} / \mathrm{min}$, which falls within the "optimal" processing window [9]. The XLPE films were all degassed under dynamic vacuum at $60^{\circ} \mathrm{C}$ for 1 week [5] prior to testing.

\subsection{CHARACTERIZATION}

Differential scanning calorimetry (DSC) was performed using $\sim 5 \mathrm{mg}$ samples in a Perkin Elmer DSC-7 instrument. Before use, the instrument was calibrated with high purity indium and all scans were performed at $10 \mathrm{~K} / \mathrm{min}$. Scanning electron microscopy (SEM) samples were chemically etched for $4 \mathrm{~h}$ to provide contrast. This was performed using a standard permanganic reagent composed of $1 \%$ potassium permanganate in an acid mixture composed of 1 part water, 2 parts phosphoric acid and 5 parts sulfuric acid as discussed elsewhere [6,7]. The samples were recovered, mounted onto SEM stubs, sputter coated with gold and then examined using a Philips XL30 ESEM operated at $15 \mathrm{kV}$.

Electrical conductivity measurements were undertaken on $0.2 \mathrm{~mm}$ thick samples at 25 and $60{ }^{\circ} \mathrm{C}$ using opposing $20 \mathrm{~mm}$ diameter electrodes and an applied field of $25 \mathrm{kV} / \mathrm{mm}$. DC breakdown testing was carried out using a ramp to breakdown test according to ASTM D149-87 [7]. An increasing DC voltage $(100 \mathrm{~V} / \mathrm{s})$ was applied to $0.1 \mathrm{~mm}$ thickness samples held between opposing $6.25 \mathrm{~mm}$ diameter chrome steel ball bearings immersed in a bath of Dow Corning 200/20cs fluid. The ball bearings were changed every 10 tests and for each material, 20 separate breakdowns were performed and the data processed using Weibull statistics. Space charge measurements were performed on $0.25 \mathrm{~mm}$ thickness samples using the PEA method [4]. A 5-Lab PEANUTS system was employed and calibration was performed at $1 \mathrm{kV}$. A poling field of $25 \mathrm{kV} / \mathrm{mm}$ was then applied and charging measurements were recorded over 1 hour. The poling field was then switched off and the charge decay behavior was then followed.

Dynamic mechanical analysis (DMA) was carried out using a TA instruments Q800 analyzer in single cantilever mode at a fixed frequency of $1 \mathrm{~Hz}$ on $1 \mathrm{~mm}$ thickness samples and a temperature scan rate of $5 \mathrm{~K} / \mathrm{min}$.

\section{RESULTS}

\subsection{DSC AND MORPHOLOGY}

Differential scanning calorimetry. Typical DSC melting curves are shown in the upper half of Figure 1. XLPE shows a transition at $103{ }^{\circ} \mathrm{C}$ (enthalpy $90 \mathrm{~J} / \mathrm{g}$ ) [5], whilst both polyethylene and polypropylene blends melt at higher temperatures. PE20s and PE20d have two melting endotherms (105 and $125^{\circ} \mathrm{C}$ ) corresponding to the LDPE and HDPE components respectively [6,7], with a total enthalpy of $120 \mathrm{~J} / \mathrm{g}$. In contrast, PP50s and PP50d both show a melting transition at a much higher temperature as expected [14] $\left(\sim 160{ }^{\circ} \mathrm{C}\right.$, total enthalpy $\sim 70 \mathrm{~J} / \mathrm{g})$. PP50s undergoes significant reorganization during the DSC scan, as evinced by a bimodal transition, indicating that less stable crystals are formed under these relatively rapid crystallization conditions in the absence of DBS [15]. The clear absence of any lower temperature features 


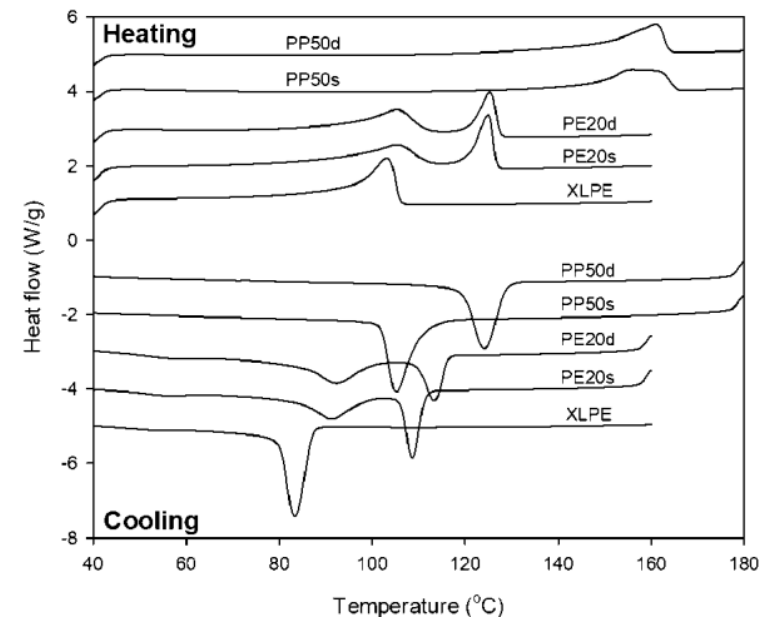

Figure 1. DSC data (curves displaced for clarity); upper set heating, lower set - cooling.

indicates that both propylene components have efficiently cocrystallised as required [6].

The cooling curves shown in the lower half of Figure 1 show that the XLPE crystallizes around $85{ }^{\circ} \mathrm{C}$ whilst PE20s exhibits twin exotherms associated with the HDPE $\left(109^{\circ} \mathrm{C}\right)$ and LDPE $\left(92{ }^{\circ} \mathrm{C}\right)$ components crystallizing in turn. In PE20d the peak associated with the LDPE is unchanged whilst that of the HDPE is moved to $113{ }^{\circ} \mathrm{C}$ indicating earlier crystallization. In contrast, PP50s and PP50d both exhibit singular exotherms at 105 and $124^{\circ} \mathrm{C}$ respectively confirming that their components are efficiently co-crystallising as required. Thus polyethylene and polypropylene blends both crystallize progressively earlier than XLPE and the DBS induces earlier crystallization (i.e. nucleates the polymer) $[15,16]$.

Morphology. At the relatively high cooling rate used here, XLPE (Figure 2a) exhibits a largely featureless texture at SEM resolution; the crosslinked network is clearly impeding any long-range crystalline ordering. In contrast, PE20s (Figure 2b) shows the expected banded spherulites of $10 \mu \mathrm{m}$ diameter [68], whilst PE20d (Figure 2c) shows a highly nucleated texture. Here crystals of HDPE have epitaxially nucleated and grown off the underlying DBS fibrils to give row like structures which are referred to as "shish kebabs" elsewhere [15]. Clearly, in the polyethylene system, two things are happening; (a) crosslinking of the XLPE is inhibiting spherulitic formation, (b), the DBS is causing massive nucleation resulting in non-spherulitic textures. The observed textures are entirely consistent with other studies on similar polyethylene systems [5-9, 15].

Figure 3 contains micrographs obtained from PP50s and PP50d. PP50s (Figure 3a) shows evidence of broad open spherulites and, most notably, exhibits a single-phase texture with no evidence of spherulitic boundaries. Elsewhere [14] it was shown that phase separation and distinct spherulitic boundaries (arising from incompatible blend components) results in degraded dielectric performance - this has been avoided here by the careful selection of blend components. In contrast, PP50d (Figure 3b) shows a highly nucleated texture devoid of any obvious spherulitic development. Characteristic linear channels, along with distinct pits, evince the presence of
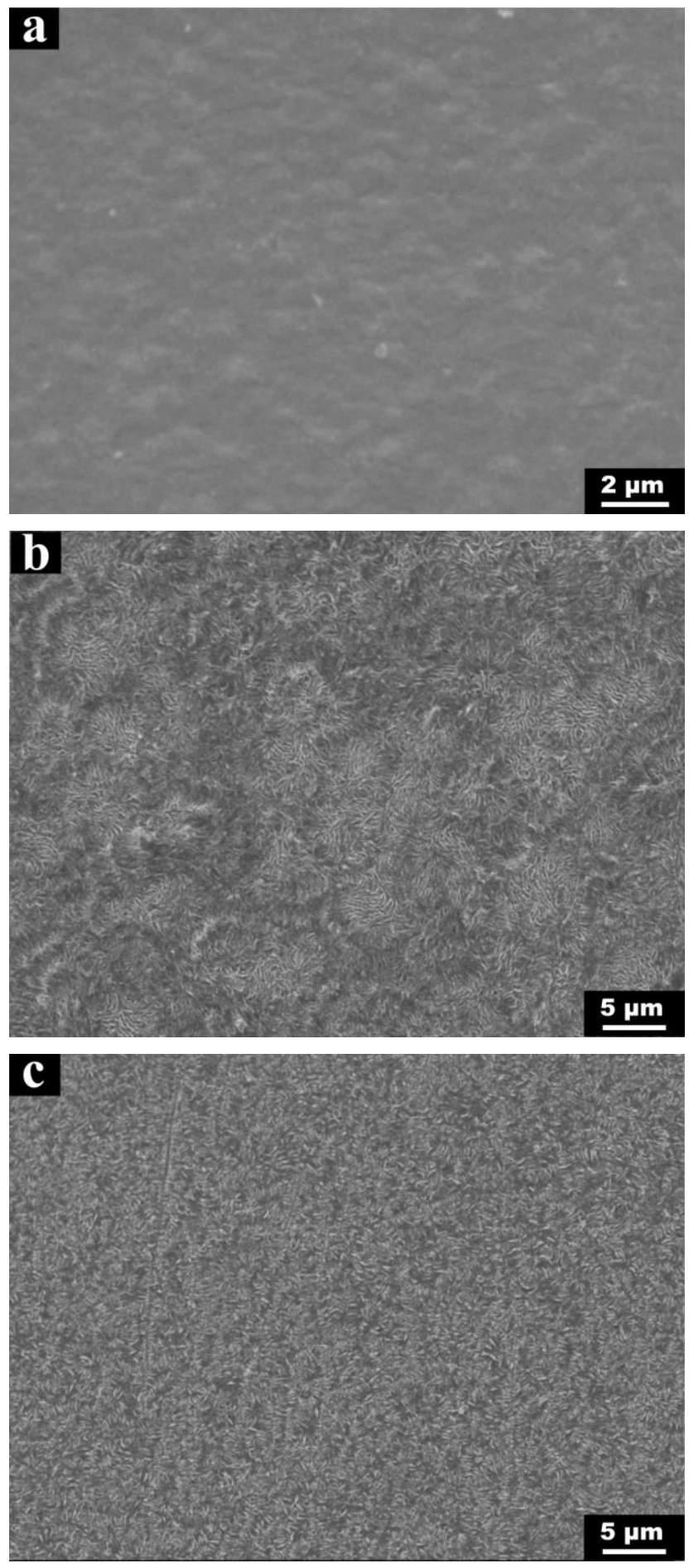

Figure 2. SEM micrographs of polyethylene systems; (a) XLPE, (b) PE20s, (c) PE20d.

the DBS; both these surface features arise from the etchant preferentially attacking the DBS fibrils [16].

\subsection{ELECTRICAL PROPERTIES}

Electrical conductivity. Figure 4a shows measured electrical conductivity values at two different temperatures. At room temperature (closed symbols) the conductivity of all five systems fall below the noise threshold of the equipment $\left(<10^{-16}\right.$ 

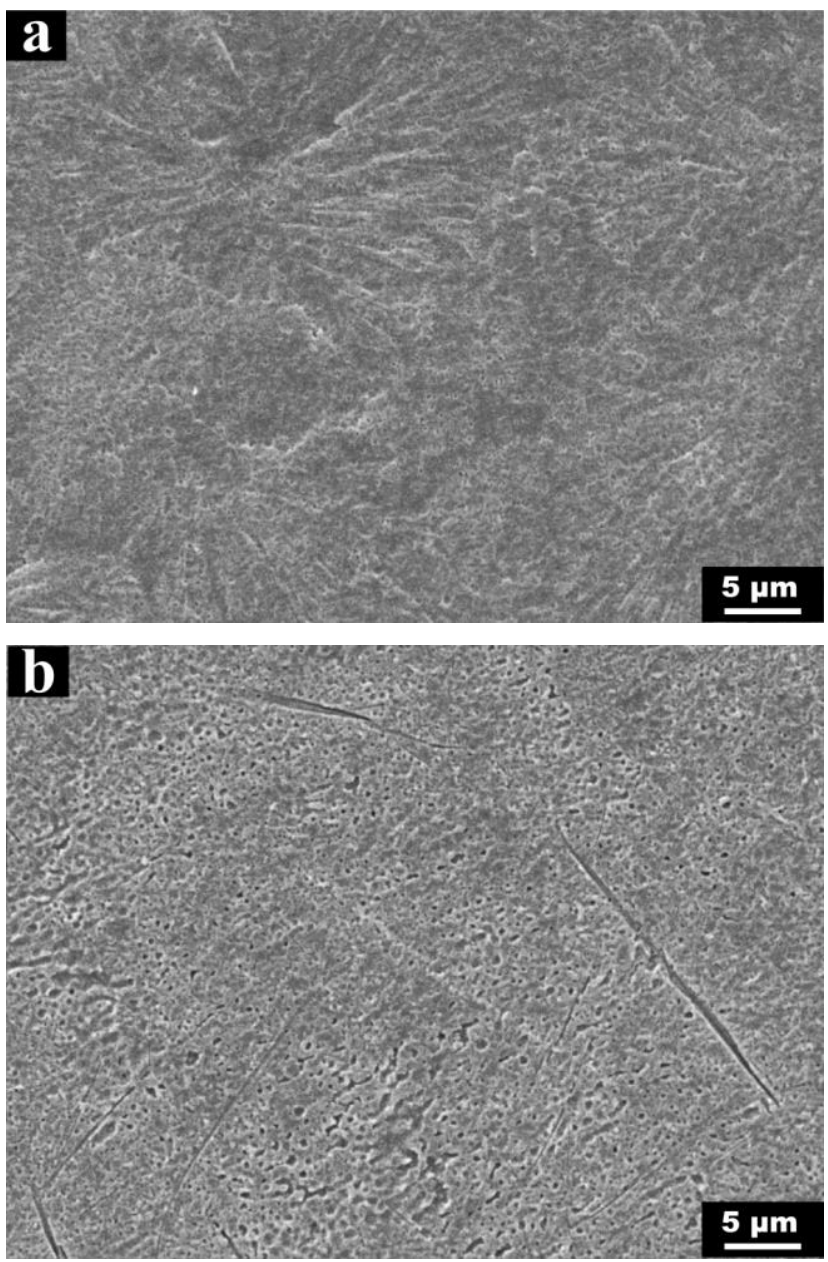

Figure 3. SEM micrographs of polypropylene systems; (a) PP50s, (b) PP50d.

$\mathrm{S} / \mathrm{cm}$ ) and, therefore, the various systems all apparently exhibit the same behavior. However, at $60{ }^{\circ} \mathrm{C}$ (open symbols), the conductivity is increased and several observations can be made. Firstly, after $\sim 200$ s the conductivity of the three ethylene-based systems is obviously higher than that of the two polypropylene blends. Secondly, PE20s appears to have a reduced conductivity relative to the XLPE reference. Since the same LDPE was used to formulate both systems, this behavior suggests two things; (a) cross-linking by-products in the XLPE may be increasing its conductivity [18], (b) the lamellar texture of PE20s is serving to impede charge transport [19]. Thirdly, the addition of DBS results in a slight uplift in conductivity in PE20d and the same uplift in conductivity is also suggested by comparing the traces from PP50s and PP50d. To our knowledge, no comparable studies of the role of DBS on electrical conductivity exist in the literature so we would speculate that this effect is due to the ability of the DBS to form an extended nanofibrillar network, which plays a role in influencing the charge transport dynamics [20].

At a constant poling voltage, it clearly takes some time for the conductivity value to approach steady state conditions. Here this is due to a combination of two factors; (a) short-term effects due to the time taken for the sample to reach thermal equilibrium with the oven following insertion, (b) dielectric
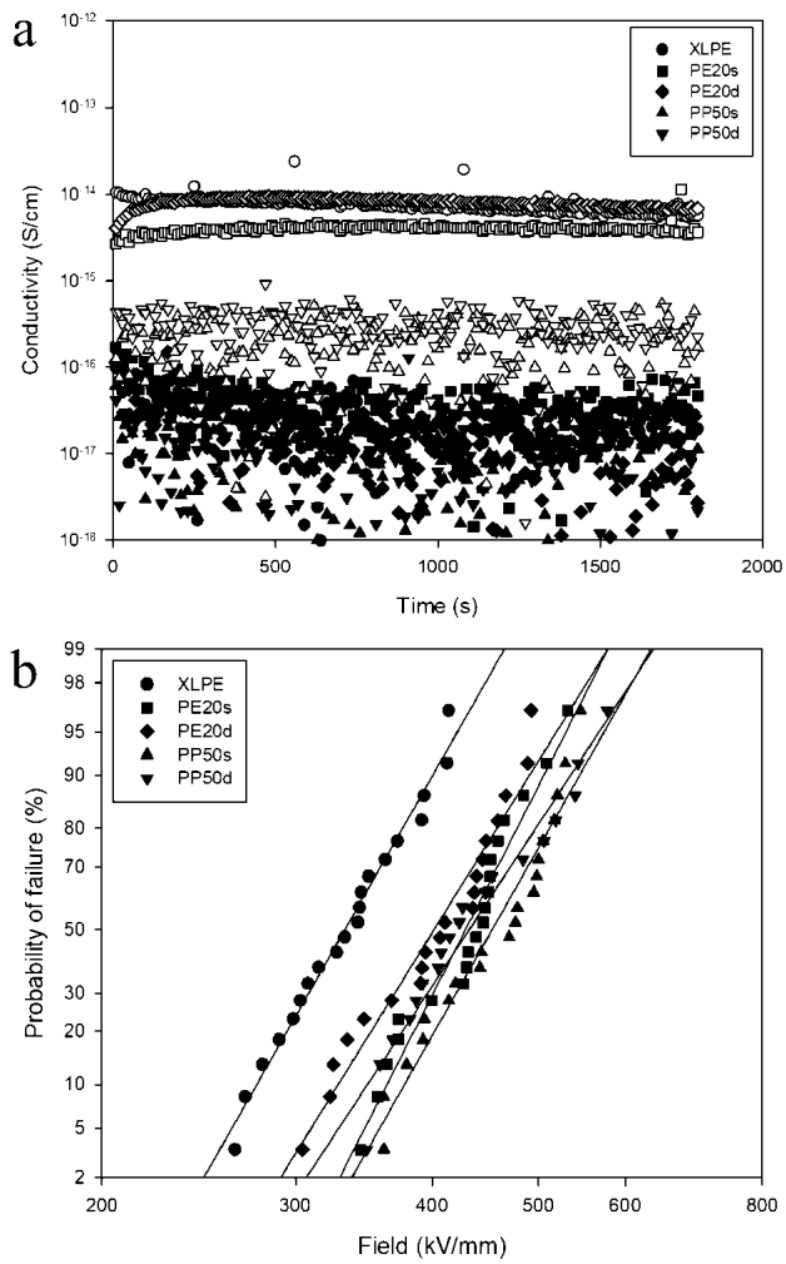

Figure 4. Electrical measurements; (a) plot of electrical conductivity at $25^{\circ} \mathrm{C}$ (closed symbols) and $60^{\circ} \mathrm{C}$ (open symbols), (b) Weibull plots from DC breakdown testing performed at $25^{\circ} \mathrm{C}$.

polarization and other long-term effects. As shown in Figure $4 \mathrm{a}$, the conductivity continues to decrease even towards the end of the testing period. Elsewhere this process is reported to take weeks or even months [21] making a determination of the steady state value of electrical conductivity very difficult. In this study we are not seeking to provide absolute values of conductivity but rather to provide a comparison between the various material formulations within a sensible experimental timescale. Complementary dielectric spectroscopy was also performed on all the blend systems but this technique did not show any significant differences between the formulations and hence the results are not presented here.

Electrical breakdown strength. Figure $4 \mathrm{~b}$ shows Weibull plots and Table 2 contains numerical data obtained from DC breakdown testing. XLPE has a measured breakdown strength

Table 2. Weibull parameters from DC breakdown testing.

\begin{tabular}{c|c|c}
\hline Sample & $E_{o}(\mathrm{kV} / \mathrm{mm})$ & $\beta$ \\
\hline XLPE & $355 \pm 22$ & 8.2 \\
PE20s & $453 \pm 25$ & 9.7 \\
PE20d & $429 \pm 27$ & 8.7 \\
PP50s & $482 \pm 29$ & 9.7 \\
PP50d & $467 \pm 34$ & 6.7 \\
\hline
\end{tabular}


of $355 \mathrm{kV} / \mathrm{mm}$ whilst PE20s has a significantly enhanced breakdown strength of $453 \mathrm{kV} / \mathrm{mm}$, an increase of some $27 \%$.

Since breakdown strength depends on sample thickness and test geometry, the current results can only be meaningfully compared to other work performed in our laboratory using the same sample thickness and testing geometry. In comparable AC tests [6-8] the breakdown strength was increased by around $20 \%$ in a blend relative to a LDPE reference material; the DC values here are approximately 2.5 times the reported $\mathrm{AC}$ values. DC breakdown testing on analogous polyethylene blends yielded values of $480 \mathrm{kV} / \mathrm{mm}$ [22] and $425 \mathrm{kV} / \mathrm{mm}$ [23] with comparable $\beta$ values. Thus, the same trends, seen previously under AC conditions, are reproduced here under DC conditions. Adding DBS reduces the breakdown strength to $429 \mathrm{kV} / \mathrm{mm}$ but this still represents an enhancement over the XLPE reference material of some $21 \%$. The propylene blends generally outperform the ethylene blends, which agrees with similar testing under AC conditions [14] where, again the inclusion of DBS brings a reduction in the breakdown strength. Nevertheless, all four blends significantly outperform the XLPE reference material.

Space charge. Figure 5 shows typical space charge results from XLPE and all four blends. In charging measurements (Figure 5a), the curves are largely dominated by the polarization peaks
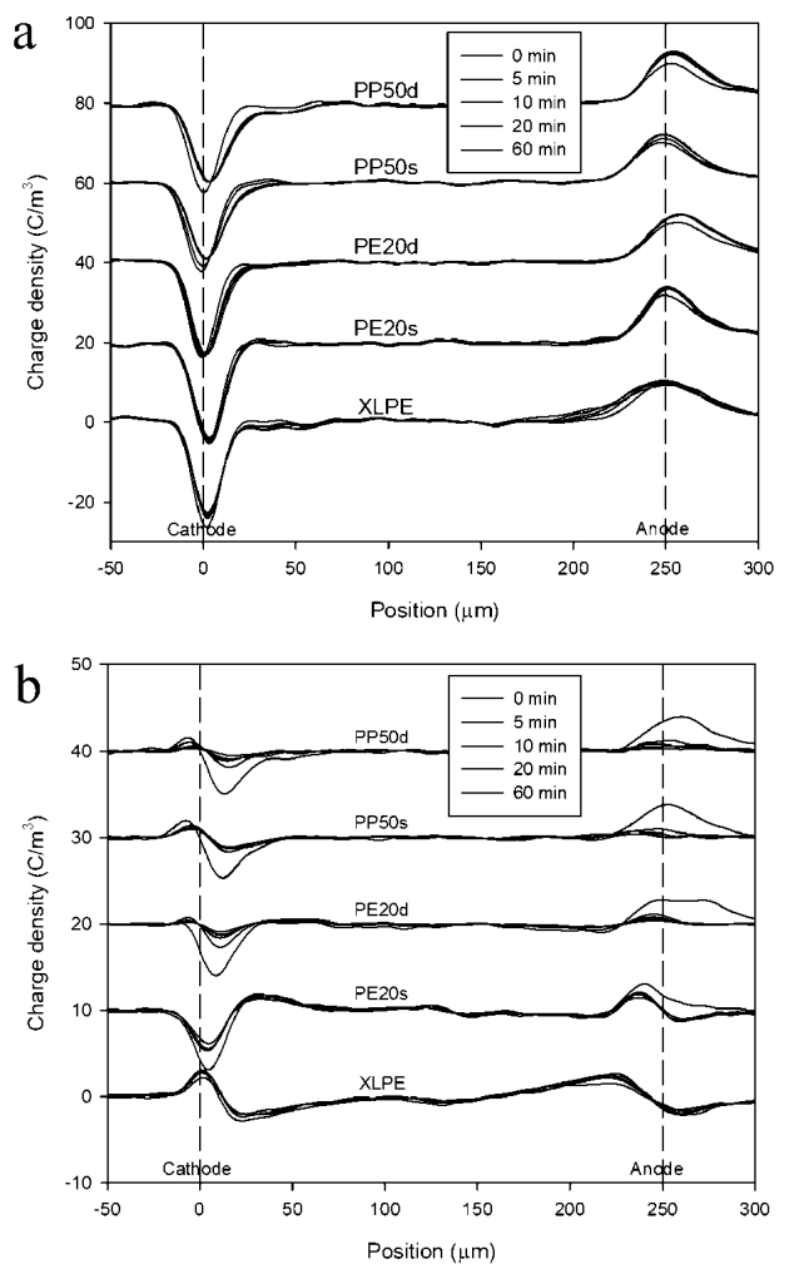

Figure 5. Space charge measurements; (a) charging, (b) decay. at the cathode and anode; however, in XLPE a significant amount of homocharge is evident at the anode, which is not immediately apparent in the other formulations. Crucially, the lack of obvious heterocharge accumulation in XLPE is evidence that the imposed degassing procedure was adequate $[4,5]$, whilst the general appearance of homocharge in the blends is consistent with other studies [23, 24]. In subsequent decay measurements, the stored charge can be clearly seen (Figure 5b). Here, significant homocharge is evident in XLPE near both electrodes, which penetrates for some distance $(\sim 25$ $\mu \mathrm{m})$ into the dielectric and does not appear to dissipate significantly over the timescale of the measurements. In the blend systems, the charge is localized to within $10 \mu \mathrm{m}$ of the electrodes and some charge dissipation is evident even in the systems prepared without DBS (Figure 5b). The development of a morphology composed of distinct crystalline and amorphous regions is a major contributing factor for the development of shallow traps as opposed to deep traps [24]. These would more readily trap and release charge contributing to the observed improvements in the space charge behavior of the blends relative to the XLPE.

DBS works in the same way in both the polyethylene and polypropylene blends - it speeds the dissipation of stored charge such that in PE20d and PP50d little or no stored charge is evident after $20 \mathrm{~min}$. Clearly, the nanofibrillar network
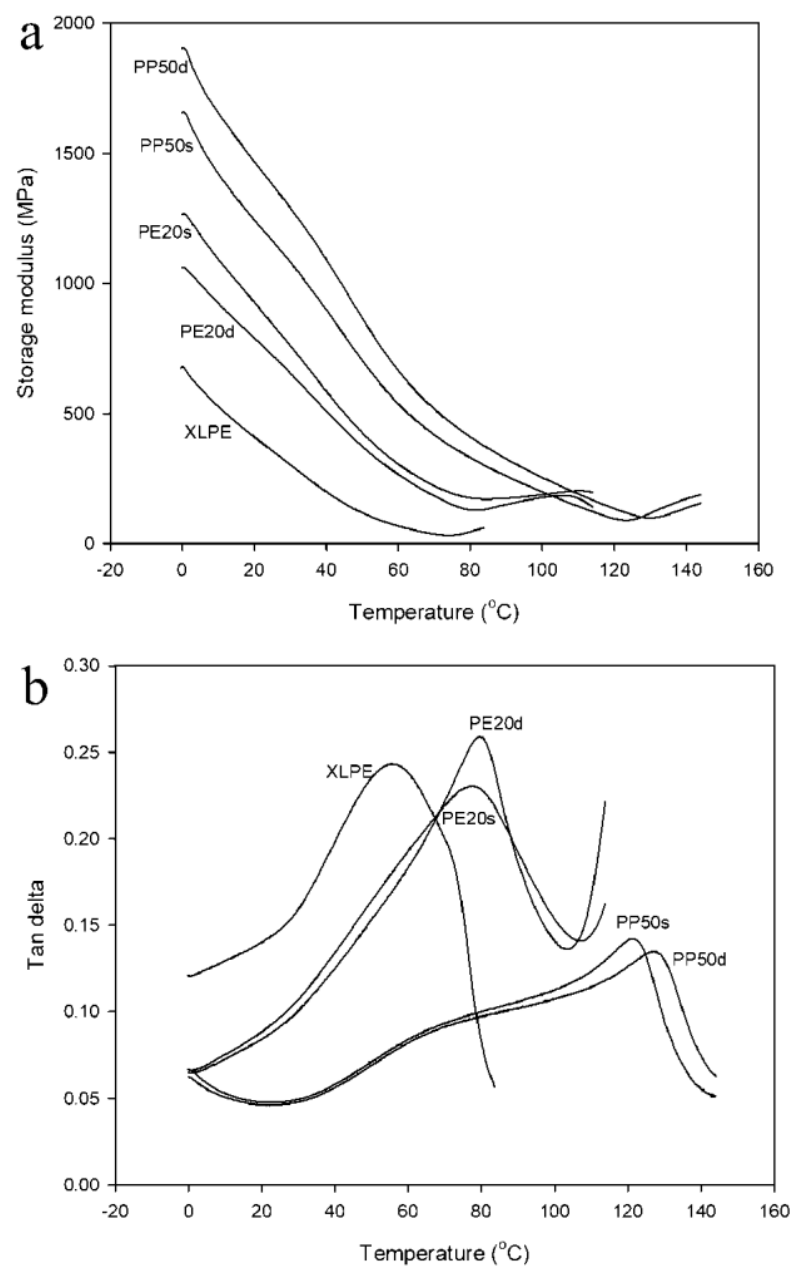

Figure 6. DMA measurements; (a) storage modulus, (b) Tan $\delta$. 
brings additional benefits, providing enhanced charge dissipation once the poling voltage is removed [16]. It is clear that all four blends offer significantly improved space charge performance relative to the reference XLPE.

\subsection{MECHANICAL PROPERTIES}

From the perspective of potential cable applications, thermomechanical performance of insulation systems is an important consideration and, therefore Figure 6 presents results from DMA measurements from the minimum accessible temperature of $0{ }^{\circ} \mathrm{C}$ to the melting point. All of the blends have a higher modulus than XLPE (Figure 6a), which may be detrimental in terms of cable installation at low temperatures, however each maintain their mechanical integrity to much higher temperatures $\left(>100{ }^{\circ} \mathrm{C}\right)$ making them much more suitable for high temperature operation than XLPE $[6,8,14]$. In this regard, the polypropylene blends offer superior performance extending the useful range to at least $130{ }^{\circ} \mathrm{C}$.

Another way of looking at this is to consider that the blend systems offer comparable mechanical properties to XLPE when run some $30^{\circ} \mathrm{C}$ hotter in the case of the polyethylene blends. In the polypropylene blends, this is extended to more than $50{ }^{\circ} \mathrm{C}$, representing a significant enhancement to the potential cable operating temperature window. This is borne out by reference to the $\tan \delta$ measurements (Figure 6b), which show a pronounced loss peak at $56{ }^{\circ} \mathrm{C}$ in XLPE, whilst, in the polyethylene blends, this is extended to $\sim 80{ }^{\circ} \mathrm{C}$ and, in the polypropylene blends, enhanced even further to $>120^{\circ} \mathrm{C}$. Thus, the point at where optimal viscoelastic behavior is attained is shifted to higher temperatures in the blends. Finally, the loss peak is enhanced in the two blends containing DBS (i.e. PE20d and PP50d) compared to their counterparts prepared without DBS. Thus, the DBS network is having a clear beneficial effect on the mechanical properties [25].

\section{CONCLUSIONS}

Two polyethylene and two polypropylene blends, along with an XLPE reference material, were crystallized under nonisothermal conditions. Previous studies showed that the nonisothermal cooling rates selected are optimal for improved electrical breakdown performance and morphological studies confirmed this.

Both sets of blends offered higher melting materials with reduced electrical conductivity, improved space charge performance and significantly higher DC breakdown strength than XLPE. Compared to the polyethylene blends, the polypropylene blends considered here exhibit less ideal mechanical properties, but make up for this with improved DC breakdown strength and the ability to handle higher temperatures. The addition of DBS has a slight negative effect on the DC breakdown strength however, it permits more effective dissipation of stored charge, which may be beneficial in HVDC cable applications.

Whilst mechanical stiffness at low temperatures could be a disadvantage (and should be ascertained fully by testing at much lower temperatures than used here), the ability to retain mechanical integrity at much higher temperatures is a chief advantage of polymer blends over XLPE. This additional headroom makes them much more suitable for cable systems, that would see highly variable load patterns (i.e. renewable sourced power networks). For the transmission system operator, this translates into recyclable assets with a higher voltage and current rating for any given insulation thickness. This in turn means that more electrical power can be transmitted through the same size of cable and provides cables with a better tolerance to short-term overload events than existing XLPE designs.

Already several cable makers such as ABB and Prysmian have brought products to market which show superior performance compared to XLPE and have the additional advantage of being fully recyclable. The aim here is to complement such formulations by providing cable makers with additional design flexibility and we would therefore encourage them to prepare and fully type test mini-cables utilizing these new formulations. Where this has been carried out in the past [9] improvements in laboratory thin film samples have translated to significant improvements in the performance of such cables; we are confident that the designs presented therein can be usefully exploited in future HVDC cable systems.

\section{ACKNOWLEDGEMENT}

We would like to thank Carmel Olefins for kindly supplying the polypropylene resins used in these investigations.

\section{REFERENCES}

[1] Y. Zhou, J. He, J. Hu, X. Huang, P. Jiang, "Evaluation of polypropylene/Polyolefin Elastomer Blends for Potential Recyclable HVDC Cable Insulation Applications," IEEE Trans. Dielect. Electr. Insul., vol. 22, pp. 673-681, 2015

[2] "A European Supergrid," 7th report of session 2010-12, House of Commons Energy and Climate Change Committee, HMRC Stationary Office, London, 09/2011.

[3] V. Vahedy, "Polymer insulated high voltage cables," IEEE Electr. Insul. Mag., vol. 22, pp. 13-18, 2006.

[4] M. Fu, G. Chen, L. A. Dissado, J. C. Fothergill, "Influence of Thermal Treatment and Residues on Space Charge Accumulation in XLPE for DC Power Cable Application," IEEE Trans. Dielectr. Electr. Insul., vol. 14, pp. 53-64, 2007

[5] Y. L. Chong, G. Chen, I. L. Hosier, A. S. Vaughan, Y. F. F. Ho, "Heat Treatment of Cross-linked Polyethylene and its Effect on Morphology and Space Charge Evolution," IEEE Trans. Dielectr. Electr. Insul., vol. 12, pp. 1209-1221, 2005.

[6] I. L. Hosier, A. S. Vaughan, S. G. Swingler, "An investigation of the potential of ethylene vinyl acetate/polyethylene blends for use in recyclable high voltage cable insulation systems," J. Mater. Sci., vol. 45, pp. 2747-2759, 2010.

[7] I. L. Hosier, A. S. Vaughan, S. G. Swingler, "Structure-property relationships in polyethylene blends: the effect of morphology on electrical breakdown strength," J, Mat. Sci., vol. 32, pp. 4523-4531, 1997.

[8] L. Li, L. Zhong, K. Zhang, J. Gao, M. Xu, "Temperature Dependence of Mechanical, Electrical Properties and Crystal Structure of Polyethylene Blends for Cable Insulation," Materials, vol. 11, Art. No. 1922, pp. 1-9, 2018.

[9] C. D. Green, A. S. Vaughan, G. C. Stevens, S. J. Sutton, T. Geussens, M. J. Fairhurst, "Recyclable Power Cable Comprising a Blend of Slowcrystallized Polyethylenes," IEEE Trans. Dielectr. Electr. Insul., vol. 20, pp. 1-9, 2013.

[10] J. A. Pilgrim, P. L. Lewin, A. S. Vaughan, "Quantifying the Operational Benefits of New HV Cable Systems in terms of Dielectric Design Parameters," IEEE Int. Symp. Electr. Insul.(ISEI), 2012, pp. 261-265.

[11] D. W. Kim, K. Yoshion, T. Inoue, M. Abe, N. Uchikawa, "Influence of morphology on electrical properties of syndiotactic polypropylene compared with those of isotactic polypropylene," Jap. J. Appl. Phys. Part 1, vol. 38, pp. 3580-3584, 1999. 
[12] I. L. Hosier, L. Cozzarini, A. S. Vaughan, S. G. Swingler, "Propylene based systems for high voltage cable insulation applications," J. Phys. Conf. Ser., vol. 183, art. no. 012015, 2009.

[13] I. L. Hosier, S. Reaud, A. S. Vaughan and S. G. Swingler, "Morphology, thermal, mechanical and electrical properties of propylene-based materials for cable applications," IEEE Int. Symp. Electr. Insul. (ISEI), 2008, pp. 502-505.

[14] I. L. Hosier, A. S. Vaughan, S. G. Swingler, "An investigation of the potential of polypropylene and its blends for use in recyclable high voltage cable insulation systems," J. Mat. Sci., vol. 46, pp. 4058-4070, 2011.

[15] A. S. Vaughan, I. L. Hosier, "The effect of dibenzylidene sorbitol on the crystallisation behaviour of polyethylene," J. Mater. Sci, vol. 43, pp. 2922-2928, 2008.

[16] G. Gherbaz, G. Chen, A. S. Vaughan, "Polyethylene/Dibenzylidene sorbitol: effect of composition on space charge of polymeric insulation systems,"Ann Rep. Conf. Electr. Insul. Dielectr. Phenom.(CEIDP),2008, pp. 161-164.

[17] S. Liu , W. Gong, B. Zheng, "The Effect of Peroxide Cross-Linking on the Properties of Low-Density Polyethylene," J. Macromol. Sci. Part B: Physics, vol. 53, pp. 67-77, 2014.

[18] H. Ghorbani, M. Saltzer, F. Abid and H. Edin, "Effect of Heat-treatment and sample preparation on physical properties of XLPE DC cable insulation material," IEEE Trans. Dielectr. Electr. Insul., vol. 23, pp. 2508-2516, 2016.

[19] K. Yahagi, "Dielectric properties and morphology in polyethylene," IEEE Trans Electr. Insul. vol. 15, pp. 241-250, 1980.

[20] B. O. Okesola, V. M. P. Vieira, D. J. Cornwell, N. K. Whitelaw, D. K. Smith, "1,3:2,4-Dibenzylidene-D-sorbitol (DBS) and its derivatives efficient, versatile and industrially relevant low-molecular-weight gelators with over 100 years of history and a bright future," Soft Matt., vol. 11, pp. 4768-4787, 2015.

[21] H. Ghorbani, T. Christen, M. Carlen, E. Logakis, L. Herrmann, H. Hillborg, H, L. Petersson, J. Viertel, "Long-term Conductivity Decrease of Polyethylene and Polypropylene Insulation Materials," IEEE Trans. Dielectr.. Electr. Insul., vol. 24, pp. 1485-1493, 2017.

[22] I. L. Hosier, M. Praeger, A. S. Vaughan and S. G. Swingler, "The effects of hydration on the DC breakdown strength of polyethylene nanocomposites employing oxide and nitride fillers," IEEE Trans. Dielectr. Electr. Insul., vol. 24, pp. 3073-3082, 2017.

[23] K. Y. Lau, A. S. Vaughan, G. Chen, I. L. Hosier, A. F. Holt, K. Y. Ching, "On the space charge and DC breakdown behaviour of Polyethylene/silica nano-composites," IEEE Trans. Dielect. Electr. Insul., vol. 21, pp. 340351, 2014.

[24] B. Dang, J. He, J. Hu, Y. Zhou, "Large improvement in trap level and space charge distribution of polypropylene by enhancing the crystalline amorphous interface effect in blends," Polym. Intern., vol. 65, pp. 371379, 2016.

[25] M. Fahrlander, K. Fuchs, C. Friedrich, "Rheological properties of dibenzylidene sorbitol networks in poly(propylene oxide) matrices," J. Rheol., vol. 44, pp. 1103-1119, 2000.

Preliminary findings from this investigation were presented at the $2^{\text {nd }}$ IEEE International Conference on Dielectrics, July 1-5 2018, Budapest, Hungary.
All data published in this paper are openly available from the University of Southampton repository at https://doi.org/10.5258/SOTON/D0808

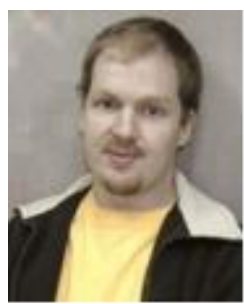

Ian Hosier received the B.Sc. degree in physics and the Ph.D. degree in polymer physics from The University of Reading, UK. He then went on with postdoctoral research at the same university, which involved extensive collaborations with institutions in Germany and Japan. In 2001 he accepted a placement at Florida State University in the USA looking at atomic force microscopy of semi-crystalline polymer blends. In 2003 he returned to the UK to take a research post at the University of Southampton looking at the aging behavior of a variety of solid and liquid insulation materials. Research interests include dielectrics, ageing, microscopy and polymer morphology.

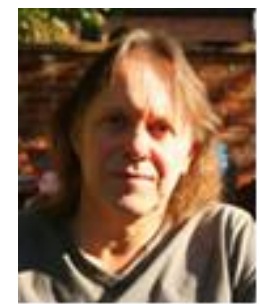

Alun Vaughan (SM'07) has a B.Sc. degree in chemical physics and a Ph.D. degree in polymer physics. After working at the UK's Central Electricity Research Laboratories and spending a period as an academic at The University of Reading, he is now Professor of Dielectric Materials and Head of the Electronics and Electrical Engineering research group at the University of Southampton. He is a former chair of The Dielectrics Group of the Institute of Physics, a Fellow of the Institute of Physics and a

Fellow of the IET.

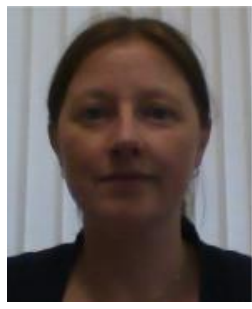

Amy Pye has an MChem in Chemistry and a Ph.D in polymer chemistry from the University of Surrey. She joined Gnosys Global in 2006 as a research scientist working on new composite materials for electrical insulation, incorporating nanomaterials into epoxy systems. While at Gnosys, Amy has been involved in a number of research programmes investigating new materials for electrical applications as well as an eclectic mixture of other application driven projects.

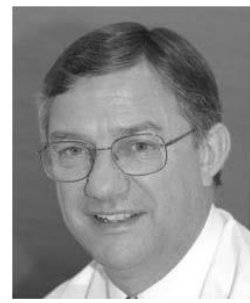

Gary Stevens (M'09) has a B.Sc. degree in physics and a Ph.D. degree in solid state polymer physics from the University of London. He is founder and Managing Director of GnoSys Global at the University of Surrey Research Park. He is a visiting professor at the same university following his previous roles as Director of the Polymer Research Centre and Professor of Polymer Science. Prior to this, he led research groups at the National Power and Central Electricity Research Laboratories. He is a member of the Institute of Physics, an EPSRC College Member and former Chairman of the Dielectrics Group and Honorary General Secretary of the UK Dielectrics Society. 